\title{
Los Vidal, una estirpe de negociantes catalanes del siglo XVIII
}

\author{
ASSUMPta Muset I PONS *
}

\begin{abstract}
RESUMEN
El objetivo de este artículo es el de analizar la evolución de una dinastía de negociantes catalanes, los Vidal, a lo largo del siglo xvill y primera mitad del xIX. Es decir, desde su aparición en Copons, esta fecunda población de la Cataluña rural, pasando por su etapa de reputados hombres del comercio castellano, hasta su definitivo retorno al Principado.

La suya fue una trayectoria brillante.

Fruto de una compleja red de alianzas tejidas a partir de pactos asociativos y familiares minuciosamente calculados.

Sus actividades comerciales se desarrollaron dentro del marco de la compañia de Manuel, Juan Vidal y Cía, una de las de más renombre del panorama vallisoletano del

Setecientos. Sus intereses les llevaron a emparentar y a aliarse, a veces de forma reiterada, con otras destacadas

\section{ABSTRACT}

The aim of this article is to analyze the evolution of a Catalan businessmen dinasty, the Vidal, throughout the 18th century and the first half of the 19th century. Firstly the beginning of the dinasty in Copons, a fecund village from the rural Catalonia, will be described.

Secontly the period of reputable castilian businessmen will also be reportard. And, finally, their return to their original country.

The Vidal dinasty followed a sucessful trajectory which was the result of a complex network of alliances.

Those businessmen calculated their associative and family agreements in a very detailed way. Their commercial activities were developed into the setting of the Company of Manuel, Juan Vidal and Co.

It was one the most famous companies in Valladolid in the 18th century.

Because of their business interests they
\end{abstract}

* Fundació Universitària del Bages (Barcelona). 
estirpes: Ios Ramon y los Jover. Originarios de Copons y residentes en Valladolid. Esta fuerte endogamia se convirtió en un arma de doble filo, que contribuyó decisivamente a debilitar su capacidad de maniobra. La extinción de una de las dos ramas familiares permitió a los Jover hacerse con el control de la firma patrimonial.

Mientras que la otra prefirió reinstalarse en Copons, donde organizó nuevos pactos matrimoniales $y$ asociativos dentro del ámbito de la próspera industria algodonera comarcal. became related by marriage and allied to other families such as the Ramon and de Jover. They came from Copons as well, and they lived in Valladolid. The strenght of the inbreeding became a powerful gun and it helped to weaken their ability of manoeuvring. One of the tow family branches was estinguished and it allowed the Jover to control the hereditary firm. The other branch preferred to be installed in Copons again. It was the location where they organized new associative pacts and marriages of conveniences within the flourishing cotton industry of the region.

La pequeña población de Copons, ubicada cerca de lgualada en la cuenca del río Anoia (Barcelona), lideró la diáspora catalana por el interior peninsular durante el siglo XVIII '. Dicho liderazgo se puso en evidencia tanto en el número de personas movilizadas (cerca de trescientas, entre 1700 y 1819), como en la rapidez y en la contundencia de dicha expansión. Sus movimientos empiezan a detectarse en los albores mismos del siglo XVIII aunque, muy posiblemente, fueron anteriores al estallido de la guerra de Sucesión. Todo hace pensar que, como mínimo, se remontan a finales del Seiscientos.

Estos arduos esfuerzos no tardaron en generar los primeros frutos. Muchas villas y ciudades españolas contaron, ya desde mediados del Setecientos, con botigues y almacenes regentados por algunas de estas estirpes de comerciantes. Unas estirpes vinculadas por intensos y complejos intereses familiares y mercantiles, tejidos a partir de la práctica de una fuerte endogamia matrimonial y asociativa. Sus imperios fueron creciendo a la sombra de complicadas redes de solidaridad y cooperación ${ }^{2}$.

1 Véase Muset I Pons, A., "Catalunya i el mercat espanyol al segle xvIll», Butlleti de la Societat Catalana d'Estudis Històrics, Vol. 5 (1994), págs. 155-162, Id., "Catalunya i el mercat interior espanyol al segle xvilı", Pedralbes, núm. 14 (1994), págs. 221-230; Id., "Catalunya y el mercado español en el siglo xVIII", en M. T. Pérez Picazo y otros (eds.), Els catalans a Espanya, 1760-1914, Barcelona, Universitat de Barcelona y Generalitat de Catalunya, 1996, págs 419-428.

2 MUSET i PONS, A., Catalunya i el mercat espanyol al segle XVIII. Els traginers i els negociants de Calaf i Copons, Barcelona, Publicacions de l'Abadia de Montserrat, 1997; Id., "La diáspora de Copons y su integración en la sociedad española del siglo XVIII", en M.T. PÉREZ PICAzO y otros (eds.), Els catalans..., págs. 429-436; e ld., "Los arrieros y negociantes de Calaf y Copons y 
Los Brunet ${ }^{3}$ en San Sebastián, los Segura en Cáceres ${ }^{4}$ y los Vidal y los Jover en Valladolid ${ }^{5}$, constituyen claros ejemplos de la importancia alcanzada por los integrantes de esta diáspora. Algunas de estas familias han sido objeto de estudio. Otras esperan aún su oportunidad.

En esta ocasión dedicaré toda mi atención a los Vidal. De hecho existen ya algunos trabajos que, de forma directa o indirecta, analizan algunas de sus actividades mercantiles. Por un lado, contamos con la investigación de I. Miguel López, centrada en el desarrollo de la compañía de Manuel, Juan Vidal y Cía. y realizada a partir de las fuentes castellanas ${ }^{6}$. Por el otro, yo misma he utilizado parte de la información que los Vidal generaron en Cataluña para estudiar el comportamiento y el funcionamiento del conjunto de la diáspora coponense ${ }^{7}$.

A través de estas páginas me propongo, pues, avanzar un poco más en el conocimiento de sus orígenes sociales y profesionales, de sus estrategias empresariales y familiares, así como de su evolución a lo largo del siglo XVIII. Para ello utilizaré información procedente de los fondos catalanes y, en concreto, de los registros parroquiales de Copons ${ }^{8}$, de los archivos notariales de las vecinas localidades de Calaf, Els Prats de Rei e lgualada ${ }^{9}$ y de los libros de contabilidad de algunos de los fabricantes y comerciantes catalanes con quienes mantuvieron correspondencia ${ }^{10}$. El período que me he propuesto analizar se extiende desde los albores del siglo XVIII hasta mediados del XIX, aproximadamente.

su implantación en el mercado español en el siglo XVIII", Revista de Historia Industrial, núm 8 (1995), págs. 193-208.

3 Garate Ojanguren, M., "La familia Brunet, San Sebastián y América", Boletín de Estudios Históricos sobre San Sebastián, núm. 24 (1990), págs. 105-134.

4 MELON, M.A., Los orígenes del capital comercial y financiero en Extremadura. Compañias de comercio, comerciantes y banqueros de Cáceres (1773-1836), Badajoz, 1992; y ld.: "Catalanes en Extremadura (1763-1872)", en M.T. Pérez Picazo y otros (eds.), Els catalans..., págs. 179-192.

5 Miguel LoPez, I., "Indicios de la presencia catalana en el comercio de Castilla y León. Manuel, Juan Vidal y Cía. (1750-1850)", en Perez PICAZO, M.T. y otros (eds.), Els catalans..., págs. 401-410. GONZALEZ ENCISO, A., "Especialización y competencia regionales: la expansión del negocio catalán en Castilla a fines del siglo XVIII’, Pedralbes, núm. 5 (1985), págs. 31-57.

Miguel LóPEz, I., “Indicios...".

MUSET I PONS, A., Catalunya....

8 Archivo Parroquial de Copons (APC) Llibres de Baptismes, Matrimonis i Òbits (1700-1850).

9 Archivo Histórico Comarcal de Igualada (AHCl) Archivo Notarial, AN, notarios de Igualada, Calaf y Els Prats de Rei (S. XVIII).

10 Archivo Histórico Municipal de Barcelona (AHMB) Fondo Comercial (FC) diversos libros de contabilidad (s. XVIII). 
Los Vidal formaban, a principios del Setecientos, una de las sagas de más raigambre de Copons. Originariamente sus miembros se distribuían en dos grandes ramas diferenciadas, según su lugar de residencia, entre los que vivían en el Raval y los que descendian de Sòl de Graus ", nombre que se atribuía a la Plaça Major o Plaza Mayor de la villa.

La primera de ellas (véase Apéndice núm. 1), que podemos calificar de menor, arranca del matrimonio formado entre Manuel Vidal, payés, y Caterina Anglada, con domicilio conyugal en el Arrabal (o Raval) de Copons. Les sobreviviría un único varón, de nombre Antoni, que cambió el ancestral oficio paterno por el de negociante, animado quizás por su boda con Ramona Roca y Pujol 12; una mujer vinculada, según todos los indicios, a dos renombradas familias locales ${ }^{13}$.

Los negocios de Antoni Vidal y Anglada debieron concentrarse en la capital vallisoletana ${ }^{14}$. Sin embargo su hijo y heredero, Valentí Vidal y Roca, se trasladó a Badajoz, donde residía en 1795. Así consta en el acta notarial rubricada por el escribano de esta ciudad Fernando Alfonso Paredes. Mediante este documento se comprometía a ceder 6.000 reales de vellón a Maria Agustina Brunet y Vidal, la menor de sus tres hermanas, casada con su colega y conciudadano Manuel Brunet y Tudó ${ }^{15}$, miembro de una de las más sólidas casas del comercio guipuzcoano ${ }^{16}$. Valentí le aventajaba en 26 años ${ }^{17}$ y la debía considerar casi como a su propia hija ${ }^{18}$. De ahí su generosidad, destinada muy probablemente a mejorar la dote paterna y asegurar su situación económica en el caso de que enviudase. Esta cesión estaba vinculada a ciertas condiciones,

"En la documentación de principios del siglo xvilı sueie añadirse, después del primer apellido, el nombre de la calle o de la plaza donde reside el individuo en cuestión, para diferenciarlo del resto de sus parientes.

12 APC, Llibre de Matrimonis, 18-1-1736.

13 Los Roca y los Pujol participaron activamente en este movimiento humano y mercantil (A. Muset i PONS, Catalunya.... Apéndice núm. 1). En este caso, sin embargo, no ha sido posible detectar el parentesco existente con la mencionada Ramona Roca y Pujol.

14 Todo hace suponer que se trata del mismo Antoni Vidal, natural de Copons y residente en Valladolid, a quien Francesc Ribas y Cía, de Barcelona, enviaba telas estampadas durante el año de 1767 (AHMB, FC, B. 122, 1767).

is APC, Llibre de Matrimonis, 16-3-1786.

16 Gárate Ojanguren, M., “La familia Brunet....”, pág. 107.

17 El chico, que recibió los nombres de Manuel, Valentí y Jaume, vino al mundo el día 8 de abril de 1742, y su hermana menor, bautizada como Ramona, María y Agustina, el 5 de enero de 1766. (APC, Llibres de Baptismes). Su madre se había casado a la edad de 16 años (APC, Llibre de Baptismes, 14-9-1719 y Llibre de Matrimonis, 18-1-1736)

18 Valentí Vidal tenía dos hermanas más: María y Teresa, casadas con dos payeses de la comarca (APC, Llibre de Testaments, 10-4-1785 y 18-5-1792). 
ya que sólo podría materializarse en el supuesto que la beneficiaria "quedase viuda, sin sucesión, aunque pas(ase) después a segundas nupcias».

No podia reclamar la mencionada cantidad si Valentí Vidal «falleciere subsistiendo (la dicha Maria Brunet) casada,... Ni se le dar(ía)n por (sus) herederos, como no se verifi(case) quedar viuda y sin sucesión» ${ }^{19}$.

De momento no sabemos nada más acerca de este Valentí Vidal ni de su otro hermano, y negociante al igual que él, Jaume, casado con Maria Tomás ${ }^{20}$.

La segunda rama, también la más importante y próspera, arranca directamente de la persona de Isidre Vidal, labrador, con domicilio en la Plaza Mayor de Copons ${ }^{21}$ (Véase Apéndice núm. 2). Dos de sus hijos (Manuel, fallecido en 1746, y Pere, en 1729) aparecen a principios del siglo XVIII ejerciendo el oficio de sastres; el tercero (Josep) era campesino como su progenitor ${ }^{22}$. De entrada, dedicaré toda la atención a la persona de Pere Vidal, consorte de Maria Pujol. El matrimonio, celebrado en $1696{ }^{23}$, tuvo un total de 9 hijos: 7 varones y 2 hembras, de los cuales sobrevivieron las dos niñas (Maria y Anna) y cuatro de sus hermanos (Francesc, Josep, Manuel y Joan) ${ }^{24}$. Todos ellos optaron, al igual que estaban haciendo muchos otros jóvenes de la villa, por dedicarse a la actividad comercial. Constituyen, en definitiva, la primera gran aportación humana de esta rama familiar.

Estas iniciativas se vieron complementadas con una política conyugal muy hábil, que les llevó a emparentarse con la mayoría de las estirpes de negociantes locales, tal como nos muestra el cuadro número 1. Así, a los vínculos de parentesco y de vecindad previamente existentes se iban agregando, progresivamente, nuevos lazos de sangre que debieron contribuir a fortalecer aún más la cohesión de los miembros de la diáspora. Dentro y fuera de Copons ${ }^{25}$.

AHCl, AN, Els Prats de Rei, F. Miralpeix, 1795, f. 208 v.

20 APC, Llibre de Matrimonis, 12-2-1771. Maria Tomàs era la hija de Sebastià Tomàs y Pujol, otro destacado negociante de Copons (Muset I Pons, A., Catalunya...., Apéndice Núm. 1).

21 Su nieto, Manuel Vidal y Pujol, se trasladaría a la calle conocida como Mitja Vila (APC, Llibre d'Obits, 20-2-1743).

22 APC, Llibre d'Óbits, 5-5-1746 y 21-8-1729.

23 APC, Llibre de Matrimonis, 18-11-1696.

24 APC, Llibres de Baptismes i Òbits, S. XVIII.

25 Véase Muset I Pons, A., Catalunya..., págs. 193 y ss. 


\section{Cuadro 1. Matrimonios realizados por los hermanos Vidal y Pujol}

\begin{tabular}{|c|c|c|c|}
\hline $\begin{array}{l}\text { Hijos de Pere Vidal } \\
\text { y Maria Pujol }\end{array}$ & Consortes & $\begin{array}{l}\text { Ocupación de la } \\
\text { familia del consorte }\end{array}$ & $\begin{array}{l}\text { Fecha } \\
\text { boda }\end{array}$ \\
\hline Maria & Josep Jover ${ }^{26}$ & Negociantes de Copons & 1722 \\
\hline Francesc & Maria Segura 27 & Negociantes de Copons & 1730 \\
\hline Josep & Maria Romeu ${ }^{28}$ & Artesanos y negociantes & 1733 \\
\hline Joan & - & - & - \\
\hline Manuel & $\begin{array}{l}\text { Ramona Roca }{ }^{29} \\
\text { (murió en 1743) }\end{array}$ & Negociantes de Copons & 1734 \\
\hline $\begin{array}{l}\text { M. Anna } \\
\text { Manuel, Vdo. }\end{array}$ & $\begin{array}{l}\text { Joan Riera }{ }^{31} \\
\text { Teresa Carbonell }{ }^{32}\end{array}$ & Negociantes de Copons & 1743 \\
\hline & (murió en 1752) ${ }^{33}$ & Labradores. de Copons & 1745 \\
\hline Manuel, Vdo. & $\begin{array}{l}\text { Manuela Felip }{ }^{34} \\
\text { (murió en 1790) }\end{array}$ & Cerero de Calaf & 1753 \\
\hline
\end{tabular}

Fuente: APC, Llibres de Matrimonis, S. XVIII.

De los siete enlaces celebrados por los vástagos de Pere Vidal, cinco comportaron el establecimiento de relaciones con otros comerciantes de la población. Todos ellos con importantes intereses en diferentes plazas españolas. Esta estrategia debió ser especialmente efectiva durante la fase inicial: la de consolidación de sus actividades dentro del mercado peninsular. Una vez superado este objetivo, se debieron imponer otras prioridades. Ello explicaría que los sucesivos matrimonios de Manuel Vidal y Pujol se concertaran, primero, con Teresa Carbonell perteneciente a una saga de labradores y hacendados de Copons, y, más tarde, con Manuela Felip hija de una próspera familia de cereros de la vecina localidad de Calaf ${ }^{36}$. Parece que se trataban, en ambos casos, de bodas que aportaban prestigio social.

26 APC, Llibre de Matrimonis, 15-9-1722. Josep Jover y Roca, negociante de Copons, y Maria Vidal fueron los padres de Pere Jover y Vidal. (APC., Llibre de Baptismes, 2-10-1727).

27 APC, Llibre de Matrimonis, 8-8-1730. En torno a las actividades mercantiles desarrolladas por la familia Segura de Copons, véase MUSET y PONS, A., Catalunya..., diversos apartados.

28 APC, Llibre de Matrimonis, 11-8-1733. El padre de Maria era tejedor, pero su sobrino Jacint Romeu y Roca fue un destacado hombre de negocios con importantes intereses en Andújar ( $A$. Muset ! Pons, A., Catalunya..., Apéndice núm. 1).

${ }_{29}$ Era la hija y la heredera universal de los bienes de su padre Francesc Roca, negociante de Copons (AHCI, AN, Igualada, V. Cots, 1734, f. 104 v. y APC, Llibre de Matrimonis, 12-1-1734).

30 Ramona Roca murió de parto, junto con su hija recién nacida (APC, Llibre d'Óbits, 20 y 22-2-1743).

31 APC, Llibre de Matrimonis, 30-1-1743. Su hijo Manuel Riera y Vidal enlazó con Maria Brunet y Segura, hermana de los Brunet y Segura de San Sebastián (APC, Llibre de Matrimonis, 11-4-1783).

32 APC, Llibre de Matrimonis, 16-2-1745.

33 APC, Llibre d'Òbits, 13-3-1752.

24 APC, Llibre de Matrimonis, 19-2-1753.

35 APC, Llibre d'Óbits, 10-4-1790.

36 Véase notas núms. 32 y 34. 
Hay una, sin embargo, que llama poderosamente la atención: la de Maria Vidal y Pujol con Josep Jover y Roca. El acto, celebrado en Copons el 15 de septiembre de $1722{ }^{37}$, marcó el inicio de una compleja y fecunda colaboración comercial y empresarial, tal como tendremos ocasión de comprobar. En todo caso éste no fue un hecho aislado, sino que se complementó con nuevas uniones conyugales destinadas a fortalecer aún más sus lazos e intereses comunes ${ }^{38}$.

Muy poca cosa sabemos acerca de las andanzas iniciales de estos jóvenes hombres de negocios. Lo más probable es que se ocuparan en la venta ambulante de manufacturas catalanas, como solían hacer la mayoría de sus compatriotas ${ }^{39}$. Una de sus principales áreas de actuación debió ser, ya desde sus inicios, la extensa meseta española; o sea, las comarcas de los antiguos reinos de Castilla y León.

Todo ello parece confirmarse gracias al pasaporte o salvoconducto sellado en Aranjuez el 25 de mayo de 1751. El documento, expedido a favor de Juan Vidal (y ¿Pujol o Romeu?) y Pedro Jover (y Vidal), mercaderes cathalanes, les facultaba para trasladarse desde "este Real Sitio a diferentes Pueblos del Reyno (par)a su comercio".

También se les permitía disponer de "armas largas para la seguridad de sus personas" ${ }^{40}$.

Es evidente que no tan sólo debían transportar suficientes mercancías y dinero como para atraer la atención de algún atracador o salteador de caminos, sino que el documento refleja también la importancia creciente de sus tratos y negocios.

Poco a poco, sin embargo, debieron ir concentrando sus actividades en el Valle del Duero, y más concretamente en la plaza vallisoletana, donde se contabilizan hasta un total de 9 miembros de esta rama familiar ${ }^{41}$. Alli mantuvieron unas frenéticas relaciones mercantiles basadas en la

37 Véase nota núm. 26.

38 En 1733 Manuel Jover y Torras, payés y negociante de Copons, se casó con Marianna Vidal y Mestre, prima hermana de los Vidal y Pujol. En 1757, se unieron Teresa Vidal y Segura, hija de Francesc Vidal y Pujol, y Manuel Jover y Romeu, y en 1778, Josepa Pradell y Vidal (nieta de Josep Vidal y Pujol) y Pere Jover y Plàcies (nieto, a su vez, del todopoderoso Pere Jover y Vidal. (APC, Llibre de Matrimonis, 15-2-1733, 2-2-1757, y Juan Vidal y Cía., después Jover y Cía. y finalmente Banca Jover, S.A., fotocopia de un texto mecanografiado cedido por el Sr. Sergi Jover). Este afamado comerciante residía en Valladolid, al igual que los Vidal, donde era considerado como uno de los comerciantes de mayor volumen de negocio del Gremio de Mercería (Gonzàlez EnCISO, A., “Especialización..., pág. 46).

39 Muset I PONS, A., Catalunya... págs. 261-266.

40 Fotocopia del documento original facilitada por el Sr. Sergi Jover.

47 Véase Apéndice núm. 3. 
comercialización de tejidos del Principado y de otras manufacturas elaboradas en diferentes centros españoles y extranjeros ${ }^{42}$.

Valladolid ofrecía, además, otros alicientes. Era una de las principales plazas de comercialización y de extracción de la rubia. El cultivo de esta planta, utilizada por la floreciente industria textil catalana, se fue extendiendo por numerosos pueblos de la zona bajo los estímulos de la Junta General de Comercio ${ }^{43}$. Las grandes familias de Copons ${ }^{44}$, con los Vidal ${ }^{45}$ y los Jover ${ }^{46}$ en cabeza, monopolizaron y dominaron su elaboración y venta.

La compañía de carácter familiar se erigió, de nuevo, como la fórmula más convincente y eficaz de desarrollar los negocios. Primero, en estrecha colaboración con sus parientes políticos: los Jover ${ }^{47}$. Y, más tarde, en solitario, arropados en torno a la alianza liderada por Manuel y Joan Vidal.

La creación de esta nueva sociedad parece remontarse a principios de los años sesenta ${ }^{48}$. Sus titulares eran, siguiendo un lógico orden jerárquico, Manuel Vidal y Pujol y su sobrino Joan Vidal y Romeu. El primero, considerado por sus vecinos de Copons como un ahombre de buena fama y costumbre y de honesta conversación" ${ }^{49}$, se convirtió en el patriarca indiscutible tras el óbito de sus dos hermanos mayores, Francesc y Josep ${ }^{50}$. Su longevidad (murió en 1792 a los 81 años de edad ${ }^{51}$ después de enviudar tres veces y de engendrar once hijos), y su fulgurante ascenso económico y social debieron garantizarle este liderazgo familiar y mercantil. El segundo pasó a

42 Miguel LoPeZ, I., “Indicios...”, págs. 404-406.

43 LaRruga, E., Memorias políticas y económicas sobre los frutos, comercio, fábricas y minas de España, Madrid, Imprenta A. Espinosa, 1787-1798, 45 Vol., Vol. 23, págs. 169 y ss. y 180 ; A. Ponz, Viaje de España, Madrid, J. Ibarra Impresor, 1772-1794, 18 Vol., Vol. 11, págs. 8 y ss.; Carrera Pujal, J. Historia política y económica de Cataluña $S$. xvi-xvili, Barcelona, Bosch Editor, 1947, 4 Vol., Vol. 4, págs. 446 y ss.; ALIER, R., "La fàbrica d'indianes de la família Canals", Recerques, núm. 4 (1974), págs. 59-91, pág. 77.

44 Véase MUSET i PONS, A., Catalunya i el comerç peninsular al segle Xvili, (Tesis Doctoral), Barcelona, 1993, págs. 337 y ss.

45 VILAR, P., Catalunya dins l'Espanya moderna, Barcelona, Edicions 62, 1966-1968, 4 Vol., véase Vol. 3, pág. 351. Vilar encuentra motivos más que suficientes para pensar que aquest Vidal sembla voler monopolitzar el mercat barceloni de la roja. También SANCHEZ, A., «L'estructura comercial d'una fàbrica d'indianes barcelonina: Joan Rull i Cia. (1790-1821)", Recerques, núm. 22 (1979), págs. 9-24, pág. 15.

46 Pedro Jover disponia de instalaciones para moler la rubia (GonzÁLEZ ENCISO, A., «Especialización...”, pág. 48).

47 Miguel LóPEZ, I., «Indicios...", pág. 403, hace referencia a la existencia de una sociedad integrada por individuos de ambas estirpes y que respondía a la denominación de Jover, Vidal y Cía.

48 Miguel LoPez, I., "Indicios...", pags. 403-404 y AHMB, FC, B. 122.

48 AHCl, AN, Igualada, J. Mateu, 1741, f. 92 r..

50 Desconocemos el momento exacto de la muerte de Francesc. La de Josep está documentada en el APC, Llibre d'Òbits, el día 28-12-1749

51 APC, Llibre d'Obits, 21-1-1792. 
ocupar, en su condición de heredero y primogénito, el lugar que su padre Josep Vidal y Pujol ${ }^{52}$ había dejado vacío.

La nutrida prole engendrada por Pere Vidal se había visto drásticamente reducida, de momento, a tan sólo dos líneas: la que encabezaba Manuel Vidal y Pujol, por un lado, y la que lideraba su sobrino Joan Vidal y Romeu, por el otro. El resto de los hermanos habían desaparecido de la escena: Joan, murió sin descendencia y Francesc, dejó, al parecer, dos únicas hijas, la mayor de las cuales acabaria esposándose con un miembro de la familia Jover ${ }^{53}$. Mientras que las otras dos hermanas de Manuel (Maria y Marianna) pasaron a formar parte de los clanes de sus respectivos maridos: Joan Riera y Josep Jover y Roca ${ }^{54}$, respectivamente.

La compañía contó, también, con la inestimable colaboración de la mayoría de los componentes masculinos de la familia Vidal. Se trataba de los individuos más jóvenes: los hijos y los hermanos menores. Incorporados en un primer momento como simples aprendices, se fueron formando bajo la atenta mirada y el sabio consejo de sus progenitores a la espera de que su mayoría de edad o la muerte del padre, en el caso de los hereus, les permitiera acceder como miembros de pleno derecho. Así, en 1769, los dos principales integrantes disponian ya de la colaboración de Pere Vidal y Roca, primogénito de Manuel, de Josep Vidal y Romeu ${ }^{55}$ y muy probablemente también de Francesc Vidal y Romeu, hermano de Joan como el anterior.

Los papeles desempeñados por los distintos socios cambiaron con el tiempo. El hecho de que Manuel Vidal y Pujol pasara algunas temporadas en Copons, desde donde debía velar por los intereses de la firma familiar, parece haber ido acompañado de un mayor protagonismo del otro socio principal. Así se desprende del otorgamiento de poderes realizado en 1766 por Manuel Vidal a favor de Joan Vidal y Romeu, a quien reconoce amplias facultades para asumir «en nombre propio de mi dicho constituyente, (como) en nombre de compañía o compañías en que yo dicho constituyente haga parte y sea interessado, y representando mi propia persona junto con él y assolas, pueda..... demandar, recibir, cobrar y haber y otorgar.... qualesquier cantidades de dinero.... que hallaré por conveniente con

52 Véase nota núm. 50.

53 Francesc Vidal y Pujol y Maria Segura tuvieron tres hijos: un niño, llamado Pere, que posiblemente debió morir durante su infancia, y dos niñas. La mayor, Teresa, enlazaria con Manuel Jover y Romeu, y la menor, Maria, con Francesc Ferrer, negociante de la Pobla de Segur (APC, Llibre de Matrimonis, 2-2-1757 y 25-1-1752).

54 Véase notas núms. 26 y 31.

$55 \mathrm{AHCl}, \mathrm{AN}$, Igualada, V. Aulet, 1769, f. $241 \mathrm{~V}$. 
interesses y premios..., según práctica y estilo de comercio.... (Y pueda) ajustar y componer.... cantidades de dinero, ropas, mercadurías y otros qualquier efectos ${ }^{56}$.

Es muy posible que años más tarde estas responsabilidades recayeran directamente en la persona de su hijo y heredero Pere Vidal y Roca ${ }^{57}$. Sólo asi se explica que, en 1769, Joan Vidal y Romeu y el mencionado Pere Vidal y Roca dispusieran de la capacidad suficiente para conceder nuevas facultades a Josep Vidal y Romeu, quien les reconoce como a sus principales. Por aquel entonces Manuel Vidal y Pujol, casado ya con su tercera esposa, la Sra. Manuela Felip y Roger, residía en su villa natal. Había sido escogido, además, como uno de los tutores de los hijos de Joan Ramon y Pujol ${ }^{58}$, un importante negociante de la localidad instalado en Andalucía ${ }^{59}$.

La intervención del patriarca de los Vidal en este asunto debió ser decisiva. Su opinión debió influir contundentemente a la hora de determinar cómo serían invertidas las 2.557 libras catalanas que el finado dejaba a sus dos hijos, aún menores de edad, y que le pertenecian como miembro de la firma Aribau, Turull y Cía., de Andújar. Esta suma fue, finalmente, incorporada a la botiga y compañía que los Vidal mantenían en Valladolid. Josep Vidal y Romeu fue el encargado de negociar la mencionada cesión.

Los Vidal se comprometieron a acoger este dinero por un período de seis años y a pagar una compensación anual de 76 libras, 14 sueldos y 2 dineros. La retribución se haría efectiva tanto si «hi ha guany com si hi ha pèrdua».

Los tutores, por su parte, renunciaron explícitamente a percibir ningún otro pago complementario en concepto de beneficios. También recibieron plenas garantías de que el capital no se vería afectado por las posibles pérdidas o quiebras que pudieran sufrir los mencionados Vidal y Cía., los

56 Ibidem, 1766, 1. $561 \mathrm{r}$.

57 Pere Vidal y Roca había asumido, con anterioridad y durante sus estancias en Cataluña, algunas obligaciones por explícita delegación paterna (AHCl, AN, Calaf, J. Novan, 1759, f. 135 r.).

58 Joan Ramon fallecíó en 1763 después de haber sufrido un aparatoso vómito de sangre que le provocó la muerte por asfixia (APC, Llibre d'Òbits, 26-12-1763). Dejó como tutores de sus dos retoños (Roc y Joan Ramon y Romeu) al ya mencionado Manuel Vidal y Pujol, a Joan Romeu, tejedor de lino de Copons, y a Valentí Selvas, pelaire de la cercana población de Sant Martí de Sesgueioles (AHCI, AN, Igualada, V. Aulet, 1769, f. 241 r.).

59 Durante los años cuarenta participó en una compañía ubicada en Granada, en estrecha colaboración con Francesc Segura, Jaume Cabriana y su padre Joan Ramon y Palau (AHCl, AN, Calaf, J. Novan, 1745, f. 42 v.). Posteriormente se incorporó a la sociedad que sus conciudadanos Josep Brufau, Ramon Aribau y Jacint Romeu tenían en Andújar (AHCl, AN, Piera, A. Alegret, 1764, f. 10 r.; Igualada, V. Aulet, 1769, f. 241 r.). 
cuales adquirieron el compromiso de devolverles las 2.557 libras más las ganancias acumuladas.

La estrategia debió beneficiar a todas las partes implicadas: a los Vidal, que asumian el cargo de socios gestores con la obligación de poner «son treball y indústria en fer anar corrent la dita botiga y companyia", porque podrian disponer de esta aportación financiera complementaria que les permitiría aumentar su volumen de negocio y su actividad mercantil; a los tutores, porque les garantizaría la rentabilidad y la seguridad de la inversión; y a los hermanos Ramon, porque verían incrementar su patrimonio con la agregación de unos beneficios fijos y libres de riesgos ${ }^{60}$.

Se iniciaba así una estrecha colaboración entre estas dos estirpes originarias de Copons. Con toda probabilidad los dos muchachos debieron adiestrarse como aprendices en las mismas dependencias de Valladolid. Cinco años y medio más tarde, es decir el 24 de agosto de 1775, recuperaron el capital inicial más los beneficios generados. La suma ascendió a un total de 2.978 libras 18 sueldos y 1 dinero ${ }^{61}$. Esto, unido a la experiencia acumulada y a la solidaridad de sus compatriotas y benefactores, debió constituir un bagaje suficiente para arriesgarse en una nueva aventura: la creación de la compañía de Juan Ramon y Hermano ${ }^{62}$. Sus integrantes eran los dos vástagos del finado Joan Ramon y Pujol: Joan Ramon y Romeu, el primogénito y ahora también flamante yerno de Manuel Vidal y Pujol, y Roc Ramon y Romeu, el benjamín, que acabaría casándose con Josepa Tomás y Ramon ${ }^{63}$.

Tal como acabamos de avanzar, sus relaciones se estrecharon aún más a raíz de la boda, acaecida el 1 de agosto de 1775, entre Joan Ramon y Manuela Vidal y Felip. El compromiso matrimonial se sumaba, de nuevo, a los numerosos intereses empresariales comunes ${ }^{64}$.

60 $\mathrm{AHCl}, \mathrm{AN}$, Igualada, V. Aulet, 1769, acta sin numerar y que aparece incorporada detrás del folio núm. $248 \mathrm{~V}$.

61 La restitución de esta cantidad se realizó el dia 24 de agosto de 1775 (AHCl, AN, V. Aulet, 1775, T. 2, f. 181 r.)

s2 Esta sociedad aparece en este mismo año de 1775 entre los clientes de los fabricantes; $B$. Cirés y Cia. y Francesc Ribas y Cia., de Barcelona (AHMB, FC, B. 271 y B. 126).

63 Véase también AHCI, AN, Calaf, J. Novan, 1785 f. 48 r.; y APC, Llibres de Matrimonis, 26-7. 1783. Josepa Tomàs era hija del Honorable Joan Tomàs y Pujol, un negociante de Copons con intereses mercantiles en Valladolid y Galicia, donde dejó algunos negocios por liquidar tras su muerte en 1790. Su yerno, residente en Valladolid, fue el responsable de liquidar todas estas cuentas y contratos. (AHCl, AN, Calaf, J. Novan, f. 261 r. 1790). Los novios tuvieron que solicitar la correspondiente dispensa papal para superar los vínculos de parentesco ( $\mathrm{AHCl}, \mathrm{AN}$, Igualada, V. Aulet, 1782, f. 229 r.).

64 El acto religioso tuvo lugar en agosto de 1775. La existencia de lazos de consanguineidad entre los dos jóvenes consortes exigió la solicitud del correspondiente permiso desde Roma. La tramitación de este documento se prolongó por espacio de cinco años, obligándoles a celebrar unos nuevos esponsales en 1780. (APC, Llibre de Matrimonis, 1-8-1775 y 23-1-1780). 
Las fuentes castellanas, trabajadas por I. Miguel López, permiten constatar la existencia de una reestructuración de la casa Vidal, iniciada en 1789 y que parece haberse dilatado hasta 1792. Estos cambios fueron motivados por una serie de acontecimientos fatídicos que afectaron a esta familia de negociantes y que influyeron decisivamente en su organigrama empresarial. Por un lado, el deceso de Joan Vidal y Romeu, que dejó como única descendencia a una adolescente que moriría a la temprana edad de 16 años ${ }^{65}$. Por el otro, la vejez de Manuel Vidal y Pujol, durante la cual tuvo que enfrentarse con toda probabilidad a la desaparición de su heredero (Pere Vidal y Roca) ${ }^{66}$, y su inminente muerte en 1792. Estos hechos reducian enormemente el potencial humano disponible. De momento, las riendas pasaban a manos de los nuevos beneficiarios, todos ellos segundones. En 1789, le tocó el turno a Josep Vidal y Romeu, soltero y sin hijos, convertido así en el nuevo jefe de esta parte de la familia ${ }^{67}$. Y, más tarde, en torno a 1792, a Manuel Vidal y Felip, casado por aquel entonces con Manuela Vidal y Felip ${ }^{68}$, única descendiente de su hermano Pere Vidal y Roca y de la mujer de éste, Maria Felip y Roger ${ }^{69}$. La desaparición de Manuel Vidal y Pujol fue acompañada, según todos los sintomas, por la designación de un nuevo representante en Cataluña. Esta misión parece haber recaído en la persona de Francesc Vidal y Romeu, que abandonó definitivamente la plaza vallisoletana para instalarse en la Ciudad Condal ${ }^{70}$. La compañía, reorganizada ahora en torno a los dos hermanos Vidal y Pujol y al primo de éstos, Manuel Vidal y Felip, tuvo que captar nuevos colaboradores fuera del ámbito familiar más intimo. No se llegó a

65 Joan Vidal y Romeu había contraído nupcias con Gertrudis Solà en 1770 (APC, Llibre de Matrimonis, 17-4-1770). De esta unión nacieron dos niñas: Gertrudis, que moriría antes de cumplir los dos años, y Maria, que lo haría a los 16 (APC, Llibre de Najxements, 29-6-1777 y 21-7-1779; Llibre d'Òbits 12-4-1781 y 19-2-1794). Su viuda volvió a casarse con Miquel Franch, curtidor de Igualada (AHCl, AN, Igualada, F. Melcior, 1794, f. 277 r.).

56 La muerte de Pere Vidal y Roca, que no aparece en los registros parroquiales de Copons, ocurrió antes de 1794. Su mujer, fallecida este mismo año, fue inscrita, precisamente, como viuda (APC, Llibre d'Òbits, 22-1-1794).

${ }_{67}$ Josep Vidal y Romeu fue nombrado heredero de los bienes de su hermano (Joan) y de los de la joven Maria Vidal y Solà (AHCl, AN, Igualada, F. Melcior, 1794, f. 281 r.).

$68 \mathrm{AHCl}, \mathrm{AN}$, Calaf, J. Novan, 1783 , f. 123 r. Y APC, Llibre de Matrimonis, 26-2-1783.

69 APC, Llibre de Matrimonis, 1-2-1757. Maria Felip y Roger era hermana de la tercera esposa del viejo Manuel Vidal y Pujol. Ambos quedaron unidos por diversos vínculos familiares: eran cuñados, por un lado, y suegro y nuera, por el otro. Murió en 1798 (APC. Llibre d'Öbits, 10-111798). Manuel Vidal y Felip se casó de nuevo con Maria Carbonell y Soler (APC, Llibre de Matrimonis, 17-2-1800).

70 En 1792 Francesc Vidal aún vivía en Valladolid, donde actuó en representación de unos fabricantes de paños de Igualada (AHCl, AN, Igualada, J. A. Mateu, 21-11-1792). En 1806 residía ya en Barceiona, desde donde envió poderes a su hermano, Josep Vidal, vecino y del comercio de Valladolid (AHCI, AN, Igualada, A Mateu Mora, 1806, f. 199 v.). 
sobrepasar, en ningún caso, el círculo de allegados relativamente cercanos, ya que el escogido fue Pau Roca y Rossich, ${ }^{71}$ emparentado con los Vidal y también con los Jover ${ }^{72}$. Era hijo de Jaume Roca y Plàcies, negociante y primo hermano de Ramona Roca y Martí, la primera mujer de Manuel Vidal y Pujol, y de Maria Plàcies, casada con Pere Jover y Vidal.

La situación se iba simplificando y las posibilidades se iban cerrando en torno a un número cada vez más reducido de candidatos, entre los cuales reaparecía con fuerza un componente de la familia Jover. Se trata de Pere Jover y Plàcies, casado con Josepa Pradell y Vidal ${ }^{73}$, sobrina de los casi extinguidos Vidal y Romeu y pariente, también, del mencionado Pau Roca. La muerte sin herederos directos de Josep, en 1817, y de Francesc, en 1830 , provocaría la concentración de esta parte del patrimonio en manos del único descendiente vivo: su sobrino Antoni Jover y Pradell, nieto de su antiguo socio y pariente, Pere Jover y Vidal ${ }^{74}$.

También la otra línea, la que derivaba de Manuel Vidal y Pujol, vivía un proceso de progresiva reconcentración. De los once hijos del viejo patriarca parece que sólo 4 de ellos, 2 hembras y 2 varones, llegaron a la edad adulta. Los chicos eran Pere Vidal y Roca, fruto de su unión con Ramona Roca, y Manuel Vidal y Felip, habido en su matrimonio con Manuela Felip y Roger.

El primero habia enlazado, en 1757 , con la ya mencionada Maria Felip y Roger, hermana de la tercera mujer de su padre ${ }^{75}$. De esta unión había nacido, en 1760, una única niña bautizada como Maria, Manuela y Ramona Vidal y Felip ${ }^{76}$. A la edad de 23 años, es decir en 1783, contrajó nupcias con su tío, y heredero de Manuel Vidal y Pujol, el Honorable Señor Don Manuel Vidal y Felip ${ }^{77}$. Tuvieron 7 hijos, siendo Pere Vidal y Vidal el primogénito y, como tal, miembro destacado de la casa Vidal de Valladolid, a la cual se incorporó en 1803 tras el deceso

\footnotetext{
Miguel López, I., "Indicios...", pág. 404.

72 Véase Apéndice núm. 4. APC, Llibre de Baptismes, 13-10-1757 y Llibre de Matrimonis, 12-1-1734 y 14-2-1751.

73 Juan Vidal y Cía... Los Pradell eran una familia de médicos. El abuelo, Jaume, ejerció su actividad en Copons. Su hijo Josep se dedicó a la medicina, como su progenitor. Contrajo nupcias con Maria Vidal y Romeu (AHCI, AN, Igualada, A. Vilades Lladó, 1777, f. 264 r., APC, Llibre de Matrimonis, 16-5-1758 y Llibre d'Óbits, 24-5-1766). Fueron los padres de la mencionada Josepa Pradell y Vidal.

74 Miguel LóPez, 1., «Indicios...", pág. 406.

75 APC, Llibre de Matrimonis, 1-2-1757. Véase nota núm. 69.

76 APC, Llibre de Baptismes, 27-10-1760.

77 Manuela Vidal, hija del Honorable Pere Vidal y Roca y de la Señora Maria Vidal y Felip, recibió como dote 3.000 libras catalanas, así como un amplio surtido de vestidos y un espléndido ajuar nupcial. Su marido era nombrado heredero universal de los bienes de sus progenitores, el Honorable Manuel Vidal y Pujol y la Señora Emmanuela Vidal y Felip (AHCI, AN, Calaf, J. Novan, 1783, f. 123 r.; y APC, Llibre de Testaments, núm. 75).
} 
de su padre ${ }^{78}$. También su otro hermano varón, Manuel, se había iniciado en el mundo de los negocios, pero su temprana muerte, a los 24 años, debió impedirle asumir cargos de responsabilidad dentro de la firma vallisoletana ${ }^{79}$.

El cuadro familiar y empresarial aparece, pues, notablemente modificado y considerablemente reducido. Ciertas prácticas, como el celibato de algunos varones (no sabemos si voluntario o inducido) y la endogamia matrimonial, junto con una elevada mortalidad infantil propia de la época, influyeron decisivamente en la evolución de estos acontecimientos. Aunque es cierto que en un primer momento habían contribuido a evitar la dispersión del patrimonio familiar y habían facilitado, en contrapartida, su concentración en manos de un grupo muy reducido de miembros, siempre del sexo masculino: los herederos. Tampoco se puede ignorar sus efectos negativos a largo plazo, al incentivar la progresiva extinción de una de las líneas familiares y el claro debilitamiento de la otra.

Por motivos que desconocemos las relaciones entre los dos nuevos socios (los Jover, liderados ahora por Pere Jover y Plàcies, y los Vidal, representados únicamente por la figura de Pere Vidal y Vidal), fueron enfriándose. En el futuro, sus pasos transcurririan por sendas muy diferentes. Así, mientras los descendientes legales de Joan Vidal y Romeu conseguían hacerse con el pleno control de la firma vallisoletana ${ }^{80}$, el sucesor directo de Manuel Vidal y Pujol iniciaba un repliegue hacia tierras catalanas. En esta decisión debió influir, sin duda alguna, su matrimonio con Ramona Jover y Amigó ${ }^{81}$, hija de Josep Jover y Galtés, un destacado fabricante de paños de Igualada cuyos posibles vínculos con los Jover de Copons son, de momento, toda una incógnita ${ }^{82}$. Una vez reinstalado en su villa natal, Pere Vidal inició una rápida reconversión hacia el sector textil en colaboración, muy probablemente, con sus nuevos parientes políticos. Sus tres hijos (Manuel, Pere y Valentí) y su yerno (Josep Tudó) ${ }^{83}$ siguieron este mismo camino, ejercitándose todos ellos en la fabricación de tejidos de algodón. Josep Tudó y Pere

78 Pere Vidal, nacido en 1791, contrajo nupcias con Maria Segura y Soler en 1807 . Él contaba 16 años; ella, 20 (APC, Llibre de Baptismes, 11-5-1791 y 21-6-1787; y Llibre de Matrimonis, 106-1807).

79 APC, Llibre de Baptismes, 11-1-1786 y Llibre d'Òbits, 14-11-1810.

8o Miguel López., I., «Indicios...”, pág. 406.

81 Pere Vidal y Vidal había enviudado en 1812, tras cinco años de matrimonio con Maria Segura y Soler (APC, Llibre de Matrimonis, 10-6-1807 y Llibre d'Obits, 11-1-1812). Su segunda esposa, Ramona Jover y Amigó. moriria en 1846 (APC, Llibre d'Öbits, 6-1-1846).

82 APC, Llibre de Baptismes, 24-9-1813.

33 JoSEP TUDÓ y LLIRÓ era un joven fabricante natural de Copons que se casó, en 1849, con Maria Vidal y Jover (APC, Llibre de Matrimonis, 21-1-1849). 
Vidal fijaron su residencia en Copons, mientras que los otros dos hermanos debieron instalarse, con toda probabilidad, en Barcelona ${ }^{84}$.

Otro punto a destacar es la clara especialización que asumieron los diferentes integrantes del grupo familiar, en función tanto de su sexo como del papel que se les asignó dentro de la diáspora. En primer lugar parece incuestionable que el negocio era un fenómeno que incumbía únicamente a los hombres y del cual las mujeres quedaban totalmente excluidas ${ }^{85}$.

Las responsabilidades femeninas venían determinadas por las características de la emigración y también por el lugar que tradicionalmente habían ocupado dentro del hogar y de la sociedad catalana. Su existencia siguió transcurriendo dentro del ámbito estrictamente local, lejos de la compañía de los maridos y de los hijos ya adultos. La inmensa mayoría de ellas envejecieron y murieron en Copons, tal como podemos apreciar en este cuadro.

Cuadro 2. Lugar de fallecimiento de los miembros de la familia Vidal (1740-1846)

\begin{tabular}{llcllc}
\hline Nombre esposo & Lugar & Año & Nombre esposa & Lugar & Año \\
\hline Manuel Vidal & & & Ramona Roca & Copons & 1743 \\
Manuel Vidal & & & $\begin{array}{l}\text { Teresa Carbonell } \\
\text { Copons }\end{array}$ & 1752 \\
Josep Vidal & Copons & 1749 & Maria Romeu & Copons & 1780 \\
Antoni Vidal & Copons & 1792 & Ramona Roca & Copons & 1785 \\
Manuel Vidal & Copons & 1792 & Manuela Feljp & Copons & 1790 \\
Pere Vidal R. & $i$ & $179 ?$ & Maria Felip & Copons & 1794 \\
Manuel Vidal F. & & & Manuela Vidal & Copons & 1798 \\
Manuel Vidal F. & $i$ & 1803 & Maria Carbonell & $i$ & $i$ \\
Manuel Vidal V. & Copons & 1810 & & & \\
Pere Vidal Vidal & & & Maria Segura & Copons & 1812 \\
Pere Vidal Vidal & $i$ & $i$ & Ramona Jover & Copons & 1846 \\
Valentí Vidal & $i$ & $i$ & Maria Tomàs & $i$ & \\
Jaume Vidal & $i$ & & & & \\
\hline
\end{tabular}

84 APC, Llibre de Baptismes, 4-4-1847 y 14-3-1748; y Archivo Municipal de Copons, (AMC) Censo de Población, nomenclatura y estadística (1842-1926), 21-5-1857.

85 No conocemos ningún caso en que alguna de estas mujeres participara en los negocios que sus maridos, padres, hijos o hermanos mantenían fuera de Cataluña. En los testamentos de estos negociantes aparecen totalmente separados los bienes que tenían en el Principado, sobre los cuales sus viudas adquírirán determinados derechos derivados de su condición de usufructuarias, y los que poseian en España, que pasaban directamente a sus herederos legales (Muset y PONS, A., Catalunya... págs. 224-225). Maria Vidal y Solà, hija de Joan Vidal y Romeu, nombró a su madre usufructuaria de las propiedades que poseía en Cathalunya, mientras que la parte que le correspondía dentro de la compañia familiar debió pasar a manos de su tío Josep Vidal y Romeu, que la había administrado desde la muerte del mencionado Joan Vidal.(APC, Liibre de Testaments, 13-2-1794 y Miguel LOPEZ, I., «Indicios...», pág. 404). 
Cuadro 2. Lugar de fallecimiento de los miembros de la familia Vidal (1740-1846) (continuación)

\begin{tabular}{|c|c|c|c|c|c|}
\hline Nombre esposo & Lugar & Año & Nombre esposa & Lugar & 70 \\
\hline $\begin{array}{l}\text { Francesc Vidal } \\
\text { Joan Vidal }\end{array}$ & $\stackrel{i}{\text { Copons }}$ & $\stackrel{i}{i}$ & $\begin{array}{l}\text { Maria Segura } \\
\text { Gertrudis Solà }\end{array}$ & $\stackrel{i}{\text { Fuera de Copons }}_{i}$ & $i$ \\
\hline Josep Vidal R. & Valladolid & 1817 & & & \\
\hline Francesc Vidal Roca & Barcelona & 1830 & & & \\
\hline
\end{tabular}

Fuente: APC, Llibres d'Òbits S. XVIII.

El sedentarismo a que quedaran relegadas estas mujeres se pone claramente de manifiesto en el hecho de que, con una sola excepción, y, aparte de los otros tres casos en los cuales desconocemos cuando se produjo el deceso, todas las demás cónyuges fueron enterradas en su villa natal. Sus maridos, a menudo, vivieron experiencias muy diferentes, ya que a algunos de ellos la muerte les debió sorprender fuera de Cataluña ${ }^{87}$.

Dicha situación se explica, en parte, por la inseguridad y las incertidumbres que rodearon la vida de las primeras oleadas de estos intrépidos negociantes. Lo más aconsejable era partir sin la compañía de la familia, es decir de los hijos pequeños y de las mujeres, que permanecerían en casa, cerca de la protección de los parientes y vecinos, asumiendo otros deberes.

Así, como esposas y madres, tenían que cumplir con su función reproductora (todas ellas dieron a luz en Copons), y con las responsabilidades posteriores relacionadas con la crianza, la formación y la educación de sus retoños. Como hijas, se convirtieron en piezas indispensables a la hora de establecer vínculos y alianzas con otras estirpes locales e, incluso, foráneas. Su papel era aparentemente pasivo, pero altamente estratégico. En un primer momento, estos pactos matrimoniales tenían como objetivo la construcción de una tupida y extensa red de solidaridades y alianzas que permitiera superar con éxito las dificultades que podía acarrear su condición de principiantes y forasteros y que asegurara, al mismo tiempo, su expansión mercantil por el interior peninsular ${ }^{88}$. Más tarde, una vez consolidados estos objetivos, se añadieron otras prioridades, tal como ya hemos mencionado anteriormente. Las dos últimas bodas de Manuel Vidal

86 Véase núm. 65.

87 Este sería el caso de Manuel Vidal y Felip, muerto en Valladolid en 1803 (MIGUEL, I., "Indicios...", pág. 410).

88 MUSET I PONS, A., Catalunya..., 193 y ss. 
y Pujol o las de su hijo, Pere Vidal, y de su sobrina, Maria Vidal ${ }^{89}$, parecen claramente encaminadas a emparentar con familias que mantenian una buena posición social, más acorde con su nuevo status.

Un status que se puso de manifiesto en numerosas ocasiones a lo largo de su vida, y también en el momento de su muerte. La adquisición de un considerable patrimonio inmobiliario formado por edificios urbanos y tierras de labranza ${ }^{90}$, el trato de Honorables Señores que recibieron Pere Vidal y Roca y su hermano Manuel Vidal y Felip y el ennoblecimiento de Josep Vidal y Romeu ${ }^{91}$, son un fiel reflejo de su próspera situación. Su riqueza afloraba, también, a través de las generosas mejoras y de las espléndidas dotes con que beneficiaron a sus viudas y descendientes ${ }^{92}$, de los fastos que solían acompañar a sus sepelios ${ }^{93}$ y de las desinteresadas donaciones que hicieron a la iglesia ${ }^{94}$.

Nos encontramos, en definitiva, delante de una familia surgida del ámbito agrícola catalán que, gracias a sus habilidades y estrategias comerciales, asociativas y familiares, consiguió encumbrarse dentro del escalafón económico y social de su época. Este ascenso fue acompañado de un parcial proceso de extinción en favor de otra importante estirpe local: los Jover, que acabarian por controlar totalmente la antigua casa Vidal de Valladolid, donde protagonizaron una notable expansión hacia aquellos

89 Véase notas núms. 32,34 y 38.

90 Los Vidal adquirieron diversas casas y propiedades agrícolas en Copons y en otras poblaciones del entorno (Rubió, Pujalt, etc.) (AHCl, AN, Igualada, diversos notarios). También en Valladolid poseían importantes bienes inmobiliarios, tal como cuenta Miguel LóPEZ, l., “indicios...", pág. 406.

91 Miguel LóPEZ, I., “Indicios...”, pág. 406.

92 Véase nota núm. 77.

93 Al entierro de Ramona Roca, primera esposa de Manuel Vidal y Pujol, asistieron 10 sacerdotes, al de la segunda, Teresa Carbonell, 6 , y al de su nuera y nieta, Manuela Vidal y Felip, 14 (APC, Llibres d'Obits, 22-2-1743, 13-3-1752 y 10-11-1798). Manuel Vidal y Pujol disponía de una tumba propia en la iglesia de Copons, situada enfrente de la capilla del Santo Cristo, donde descansaron la mayoría de sus allegados. Su tercera esposa, Manuela Vidal y Felip, prefirió ser enterrada en la capilla de la Virgen de los Dolores, por cuya imagen sentían al parecer una gran devoción (APC, Llibre d'Obits, 10-4-1790, 4-4-1797).

94 Antonio Vidal y Anglada destinó 1.000 libras catalanas, ganadas ab mon propi treball, para la creación de una fundación a favor de la iglesia de Copons (APC. Llibre de Testaments, testamento núm. 81). También Manuel Vidal y Pujol destinó una fracción sustanciosa de su patrimonio para financiar diferentes celebraciones religiosas para después de su óbito: un novenari perpetuo durante la Cuaresma, una misa cantada cada año y perpetuamente durante el viernes de la setmana de Passió, así como la obligación de cantar los gozos a la Virgen de los Dolores durante la procesión del Domingo de Ramos. Todos estos actos tenían que ir precedidos de los convenientes repiques de campanas y anuncios durante el temps dels divinals officis del diumenge antes (y) en lo toch de oració de la nit antecedent, y amenizados con la asistencia de diversos sacerdotes. Como garantía aportaba y cedia una casa y un edificio que poseía en las poblaciones de Segur y Copons, respectivamente (AHCI, AN, Igualada, J. A. Mateu, 20-10-1790) 
sectores de la economía castellana que ofrecian mayores expectativas de futuro. También los amplios contactos y las estrechas relaciones que mantenían en Cataluña fueron hábilmente aprovechados para ensanchar aún más sus horizontes empresariales, participando en diferentes proyectos a nivel regional ${ }^{95}$.

Los Vidal, por su parte, no sólo parece que se desentendieron de la vieja firma familiar y de sus negocios vallisoletanos, sino que además protagonizaron una contundente reconversión que afectó tanto a su ubicación geográfica, al abandonar el valle del Duero para reinstalarse de nuevo en Copons, como familiar, al prescindir de la política matrimonial tradicional en beneficio de nuevas alianzas, esta vez con la burguesía comarcal y empresarial, al invertir en la industria textil en detrimento de las operaciones exclusivamente comerciales.

Terminaba así una larga etapa de casi cien años durante la cual no sólo se habían abierto camino dentro del mercado español, donde disfrutaban de un merecido prestigio, de un respetable crédito y de una densa red de contactos, sino que además habían conseguido labrarse unas sólidas relaciones dentro del Principado. Un patrimonio muy valioso y totalmente imprescindible para poder prosperar en esta nueva experiencia como empresarios del sector textil catalán.

95 Joan Vidal y Cía...; ANes Ál varez, R. y de Otazu y Llana, A., El Banco Herrero. 75 años de historia (1912-1987). Madrid, Gráficas Enar, 1987, págs. 18 y ss.; e MiGUEL LóPEZ, I., “Indicios...”, págs. 406 y 407. 


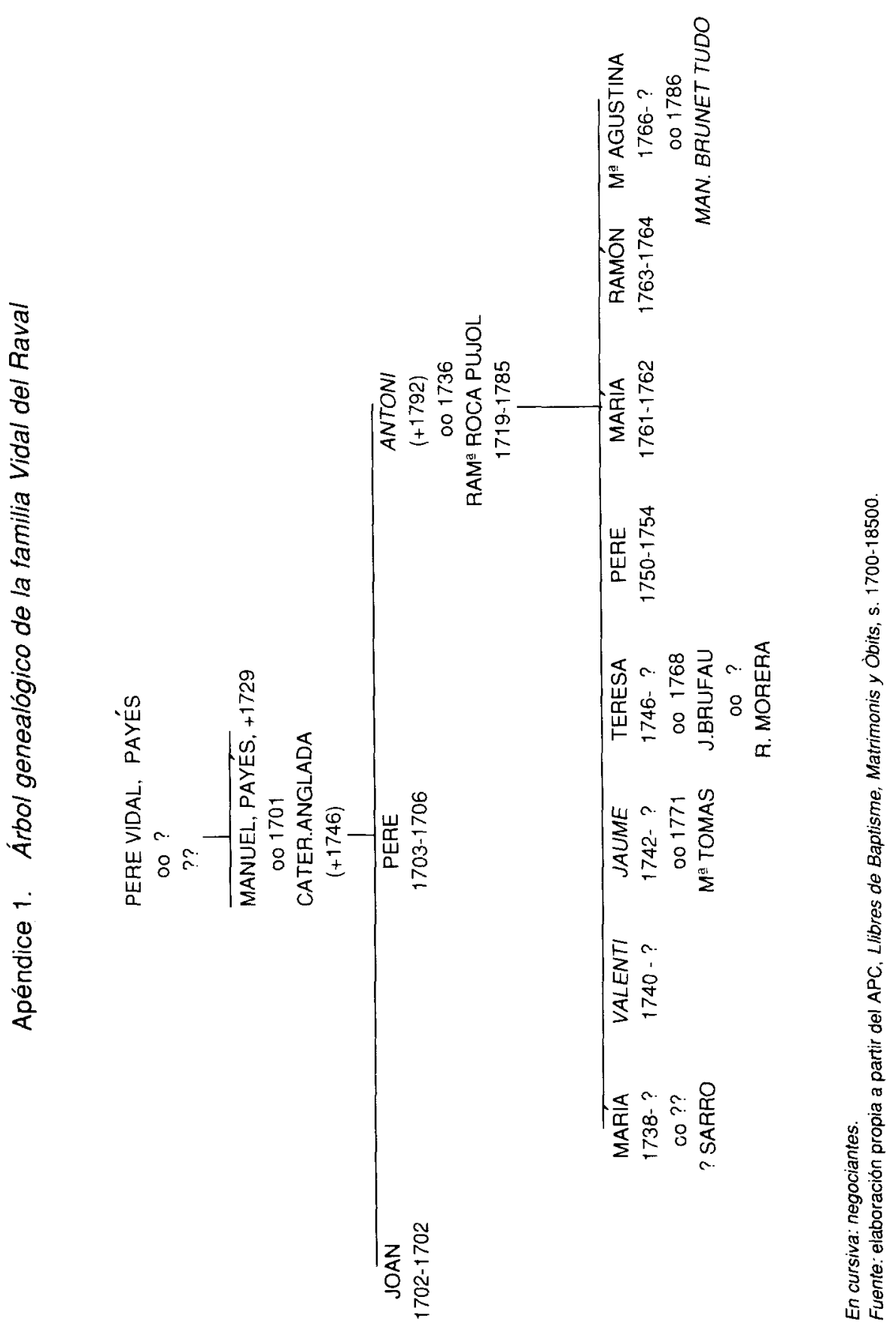




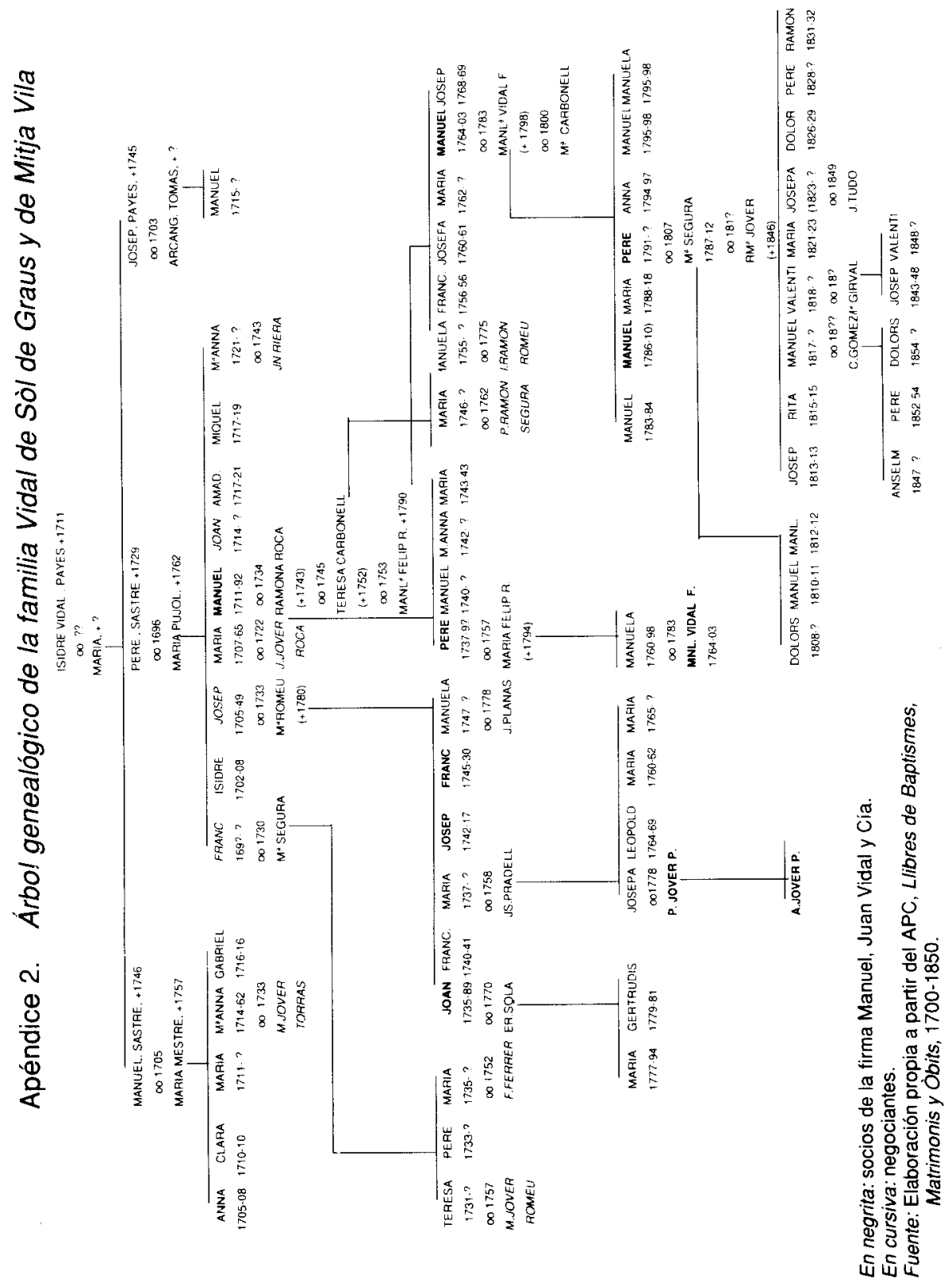


Apéndice 3. Negociantes miembros de la familia Vidal de Copons (1700-1850)

NOMBRE

FAMILIA VIDAL DEL RAVAL

VIDAL ANGLADA, ANTONI

VIDAL ROCA, JAUME

VIDAL ROCA, VALENTI
PLAZA

CRONOLOGÍA
VALLADOLID

BADAJOZ
$1730-1790$

$1770-?$

$1790-?$

FAMILIA VIDAL DE SOLL DE GRAUS Y MITJA VILA

VIDAL PUJOL, FRANCESC

VIDAL PUJOL, JOSEP

VIDAL PUJOL, MANUEL

VIDAL PUJOL, JOAN

VIDAL ROMEU, JOAN

VIDAL ROMEU, JOSEP

VIDAL ROMEU, FRANCESC

VIDAL ROCA, PERE

VIDAL FELIP, MANUEL

VIDAL VIDAL, PERE

VIDAL VIDAL, MANUEL

$\begin{array}{ll} & 1730-? \\ \text { VALLADOLID } & 1730-1749 \\ \text { VALLADOLID } & 1730-1792 \\ \text { ARANJUEZ-VALLAD-ORENSE } & 1730-? \\ \text { VALLADOLID } & 1760-1789 \\ \text { VALLADOLID-MADRID } & 1760-1817 \\ \text { VALLADOLID-BARCELONA } & 1760-1830 \\ \text { VALLADOLID } & 1760-179 ? \\ \text { VALLADOLID } & 1780-1803 \\ \text { VALLADOLID } & 1800-18 ? ? \\ & 1800-1810\end{array}$



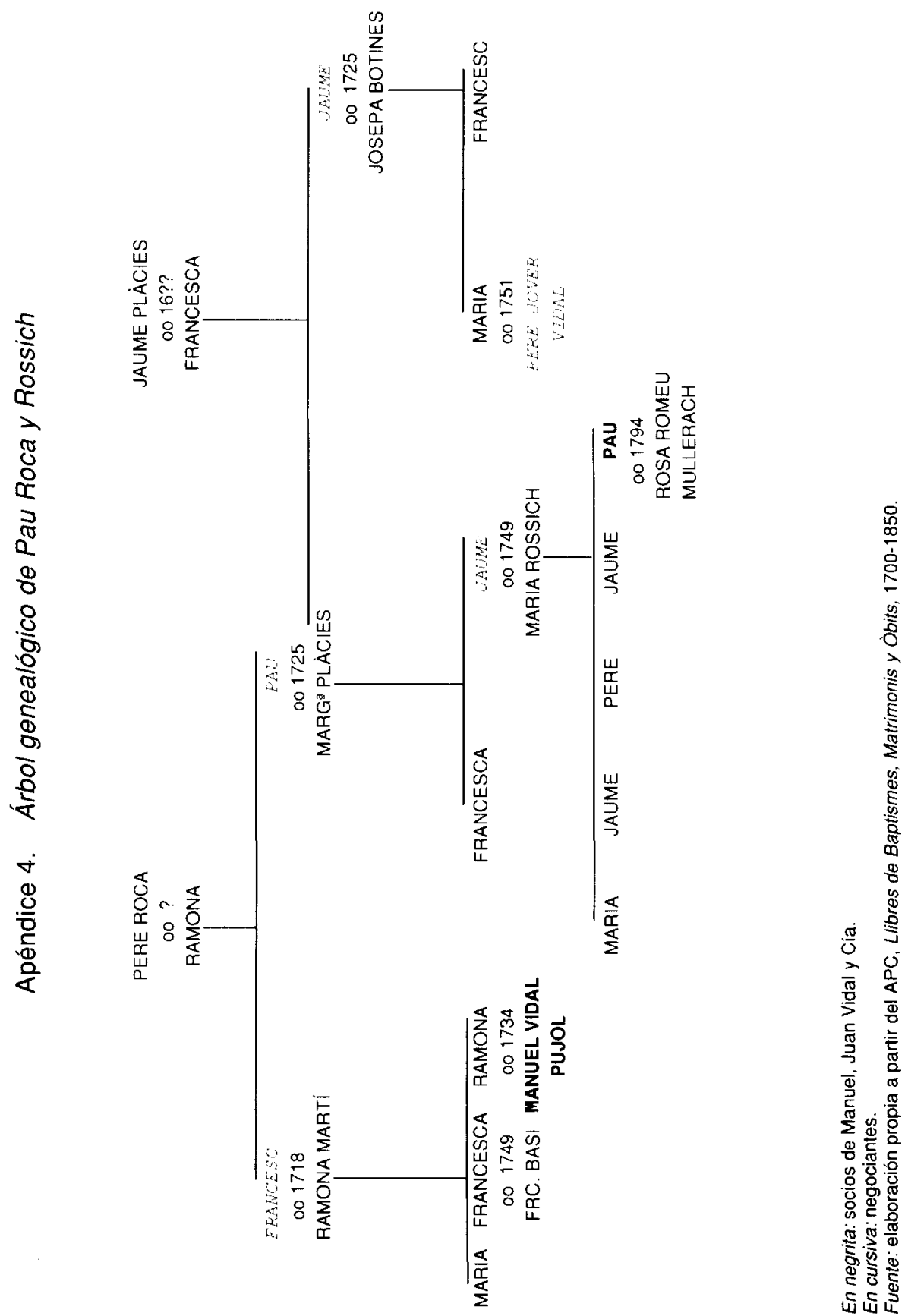